\title{
Terapia Celular no Tratamento da Insuficiência Cardíaca Isquêmica
}

\author{
Marlos R. Fernandes ${ }^{1}$, Guilherme V. Silva ${ }^{1}$
}

\section{RESUMO}

Neste artigo, os autores discutem o estado da arte da terapia celular no tratamento da insuficiência cardíaca isquêmica. São apresentados os principais tipos celulares disponíveis e suas particularidades no tratamento desta doença.

DESCRITORES: Terapia celular. Miocárdio. Mioblastos. Transplante de células, métodos. Insuficiência cardíaca congestiva. Isquemia miocárdica.

\section{SUMMARY}

\section{Cellular Therapy in the Treatment of Ischemic Heart Failure}

In this article the authors discuss the state of the art on cell therapy for ischemic heart failure. The principal cell types and their specific characteristics for the treatment of this pathology are presented.

DESCRIPTORS: Tissue therapy. Myocardium. Myoblasts. Cell transplantation, methods. Heart failure, congestive. Myocardial ischemia.
A s recentes mudanças propostas pelo American College of Cardiology/American Heart Association (ACA/AHA), expostas nas diretrizes para diagnóstico e tratamento de insuficiência cardíaca ${ }^{1}$, chamam a atenção da comunidade médica para a identificação precoce desta doença. De acordo com tais diretrizes, nova definição foi criada, incluindo pacientes assintomáticos, com ou sem lesão cardíaca estrutural manifesta (classe A e B, respectivamente), porém sob risco de desenvolvimento de insuficiência cardíaca. Apesar de não se desconsiderar a classificação universalmente aceita e utilizada na prática clínica proposta pela New York Heart Association (NYHA), tais mudanças expõem uma preocupação crescente com a identificação precoce dos pacientes em risco. O racional por traz desta estratégia baseia-se no fato de que, uma vez estabelecida, a injúria ventricular torna-se irreversível, fazendo portanto parecer algo tardio o diagnóstico da insuficiência cardíaca já sintomática. Atualmente, as opções terapêuticas disponíveis são voltadas para o controle

1 Texas Heart Institute at St. Luke's Episcopal Hospital, Houston, Texas, EUA.

Correspondência: Marlos R. Fernandes. Texas Heart Institute. Cardiology Research Dept/ Stem Cell Lab. St. Luke's Episcopal Hospital 6720 Betner Avenue MC 1-33 - Houston, TX, USA - 77030

E-mail: mfernandes@heart.thi.tmc.edu

Recebido em: 09/05/2006 • Aceito em: 13/02/2007 da hiperativação do sistema neurohumoral, tratamento da etiologia, quando possível, e prevenção da morte súbita (cardioversores-desfibriladores implantáveis), quando indicado.

Recentemente, a capacidade reparativa cardíaca foi demonstrada em estudos pré-clínicos ${ }^{2-4}$. A demonstração de células de origem extracardíaca, identificadas pela presença de cromossomo $\mathrm{Y}$ em pacientes do sexo masculino transplantados a partir de doadoras do sexo feminino, nos leva a questionar o paradigma vigente, o qual se baseia na incapacidade regenerativa do coração e na conseqüente substituição por tecido fibrótico após exposição a injúria miocárdica e morte celular ${ }^{4}$. Talvez, mais adequado seja pensarmos que a higidez do coração, bem como de todo sistema, é resultante de um equilíbrio entre exposição a fatores agressores e capacidade reparativa. Portanto, o dano estrutural resulta do desequilíbrio de tal homeostasia, seja por uma maior exposição à agressão crônica ou aguda (insultos isquêmicos agudos ou crônicos cumulativos), seja por uma redução da reserva reparativa (idade, diabetes) ${ }^{5-7}$.

Entretanto, é inegável a ineficácia de eventuais mecanismos naturais de reparo em condições de agressão extrema, como no caso de infarto agudo do miocárdio e, posteriormente à injúria estabelecida, no processo de remodelamento ventricular. Após a perda de cardiomiócitos, seja por insulto isquêmico e resultante necrose, seja por aumento da freqüência de apoptose associada à insuficiência cardíaca já estabelecida, a 
cavidade ventricular expõe-se a um estresse parietal aumentado. Tal estímulo confere um importante sinal para hipertrofia celular excêntrica e conseqüente dilatação ventricular ${ }^{8}$. Simultaneamente, o aumento do tônus adrenérgico contribui para a elevação da pós-carga, fechando o ciclo que leva à falência ventricular progressiva. Portanto, torna-se imprescindível o entendimento dos mecanismos fisiopatológicos envolvidos em tais processos, bem como das respostas celulares envolvidas nos possíveis mecanismos reparadores, para buscarmos opções terapêuticas que nos permitam objetivar o reparo do dano já estabelecido, ao invés do simples tratamento paliativo, o qual somente reduz a velocidade de progressão da doença.

\section{TRANSFORMANDO O MECANISMO DE REPARO MIOCÁRDICO EM UM PROCESSO EFICAZ}

Adotando uma visão simplista de um processo complexo e ainda em grande parte indefinido, podemos concluir que as respostas intrínsecas de reparo miocárdico e vascular são ineficazes. A melhor forma de se atuar na recuperação miocárdica após o estabelecimento da injúria seria influenciando tais respostas no sentido de transformá-las em mecanismos eficazes. Se o insulto isquêmico resulta em morte de miócitos secundária ao comprometimento vascular e redução de fluxo de sangue regional, caso consiga-se promover angiogênese e miogênese em proporções suficientes para o restabelecimento de um estado de equilíbrio fisiológico local, impede-se que os estímulos responsáveis por promoverem a progressão da falência cardíaca se perpetuem. Sabendo-se da complexidade de tais mecanismos e reconhecendo a humildade dos nossos conhecimentos atuais, a forma mais objetiva de tratamento seria influenciar positivamente os mecanismos naturais de reparo, por meio de administração ou recrutamento local de células capazes de promoverem angiogênese e/ou miogênese ${ }^{9}$.

A intensidade da resposta regenerativa, possivelmente, relaciona-se diretamente à gravidade do processo patológico. A injúria vascular aguda desencadeia uma rápida elevação dos níveis de células endoteliais progenitoras circulantes, como demonstrado em estudos com pacientes vítimas de queimaduras ou submetidos à revascularização miocárdica cirúrgica ${ }^{10}$. Por outro lado, baixos níveis basais de tais células correlacionamse com a presença de fatores de risco de doença arterial coronária e identificam indivíduos sob risco elevado de eventos coronários adversos futuros ${ }^{11,12}$. Entretanto, no contexto crônico da cardiomiopatia isquêmica já em fase dilatada, espera-se que tais sinais para incorporação e recrutamento de células primitivas (do inglês "homing signal"), sejam de intensidade reduzida. Tal noção influencia diretamente as opções terapêuticas, como veremos em breve.

Freqüentemente, o coração em falência ventricular apresenta uma expressiva massa miocárdica viável, a qual representa uma população de cardiomiócitos hibernados. O aumento de fluxo sangüíneo para tais segmentos reverte-se em melhora de função ventricular e conseqüente redução do desequilíbrio neurohumoral, favorecendo o restabelecimento da homeostasia. Portanto, nestes casos específicos, a melhora da perfusão miocárdica pode traduzir-se em melhora de contratilidade regional e global por meio de recrutamento de musculatura viável, tendo grande impacto prognóstico por impedir o remodelamento ventricular adicional e reduzir a incidência de morte súbita ${ }^{13,14}$. Entretanto, em alguns casos não se faz possível a revascularização completa de toda área isquêmica, ou mesmo qualquer tipo de abordagem pode ser inviável, de acordo com as características anatômicas do comprometimento aterosclerótico coronário. Estes pacientes são freqüentemente classificados como "sem opção" para qualquer tipo de intervenção, seja percutânea, seja cirúrgica, tendo prognóstico sombrio e curta sobrevida, sendo o transplante cardíaco o último recurso terapêutico disponível.

Neste contexto, a terapia celular pode ser vista como uma opção terapêutica em potencial. Estudos iniciais demonstraram melhora de capacidade funcional avaliada por teste ergométrico, bem como redução do defeito de perfusão à cintilografia miocárdica, após administração intramiocárdica de células mononucleares derivadas da medula óssea (CMMO) em pacientes com disfunção ventricular isquêmica avançada, sem condições de realização de procedimentos adicionais de revascularização miocárdica, sendo tais efeitos persistentes em acompanhamento de um ano ${ }^{15,16}$. Entretanto, no momento, temos mais perguntas do que respostas e pontos importantes estão por serem definidos, como: tipo celular de escolha, dose ideal e via de administração para pacientes com cardiomiopatia isquêmica.

\section{ESTRATÉGIAS TERAPÊUTICAS:DO ISOLAMENTO DAS CÉLULAS AO MOMENTO DA INJEÇÃO}

Várias populações diferentes de células foram utilizadas em trabalhos pré-clínicos e clínicos com a esperança de obterem-se resultados positivos tanto em relação à melhora de perfusão, com conseqüente redução de isquemia, como em relação à melhora contrátil global e segmentar. Nos próximos parágrafos, abordaremos os principais tipos celulares disponíveis e suas particularidades no tratamento da insuficiência cardíaca isquêmica.

\section{Mioblastos}

Estudos clínicos foram realizados, onde pacientes candidatos à revascularização cirúrgica submeteram-se a injeção per operatória, por via transepicárdica, de mioblastos obtidos a partir de biópsia muscular e expandidos em meio de cultura ${ }^{17,18}$. A incorporação das células injetadas no tecido miocárdico nativo e a maturação de mioblastos em miócitos adultos foi demonstrada 
por análise histológica dos corações explantados, em estudos clínicos envolvendo pacientes em fila de transplante, submetidos a implante de dispositivos de assistência ventricular ${ }^{19}$. O uso de mioblastos oferece algumas vantagens, como o seu comprometimento com a linhagem muscular e, portanto, com a diferenciação em miócitos adultos, a facilidade de seu isolamento e sua rápida expansão em meios de cultura, além de sua maior tolerância à isquemia, sendo possível a obtenção de células autólogas em grande quantidade, em curto espaço de tempo. Estudos clínicos confirmaram a incorporação e diferenciação de mioblastos em miócitos adultos, traduzindo-se em uma melhora clínica e de fração de ejeção ${ }^{17,19}$. Acompanhamento por 1 e 4 anos após implante de mioblastos em tecido cicatricial de pacientes com disfunção ventricular isquêmica demonstrou resultados consistentes, com melhora de fração de ejeção e sintomas, associados a sobrevida das células enxertadas e sua diferenciação em miócitos funcionais ${ }^{20,21}$. A despeito da grande maioria dos estudos com mioblastos ter sido realizada em pacientes candidatos à revascularização cirúrgica, submetidos a injeções transepicárdicas, tal via tem nítidas limitações. Vários destes pacientes, apesar de apresentarem cardiopatia isquêmica, têm anatomia coronária impeditiva à realização de qualquer tipo de revascularização e, portanto, o risco elevado do acesso cirúrgico nestes casos não se justifica somente para a administração de células. Da mesma maneira, a injeção por via transcoronária não é possível na maioria dos casos, devido à ausência de artéria patente nos segmentos-alvo de injeção.

Recentemente, um estudo clínico de fase 1 demonstrou a segurança do uso do sistema TransAccess na realização de uma punção guiada por ultra-som via seio coronário, possibilitando a injeção intramiocárdica de células ${ }^{22}$. A comparação desta via com a cirúrgica foi posteriormente realizada, em um grupo pequeno de pacientes, revelando resultados similares em relação à eficácia ${ }^{23}$. Outra opção de acesso foi demonstrada com a utilização do sistema de mapeamento eletromecânico tridimensional, o qual fornece a vantagem de permitir a diferenciação entre tecido miocárdico viável e cicatricial, facilitando a injeção precisa no segmentoalvo $^{24,25}$. Neste estudo, foram realizadas injeções transendocárdicas com uso de cateter Myostar (sistema NOGA - Biosense Webster) e acesso vascular percutâneo em cinco pacientes com IAM anterior prévio ${ }^{20}$. Curvas de pressão-volume mostraram maior contratilidade, predominantemente devido à melhora da função sistólica, sem alteração expressiva de função diastólica. Estudo clínico em andamento permitirá comparar a eficácia das vias transendocárdica e transepicárdica para a administração de mioblastos ${ }^{26}$.

É importante ressaltar que a presença de arritmias ventriculares após o implante de mioblastos ocorreu com elevada freqüência e na maioria dos estudos realizados. Apesar de ser ainda incerto o mecanismo relacionado com tal evento adverso, as distintas propriedades eletrofisiológicas dos miócitos esqueléticos, o implante em regiões cicatriciais com fluxo reduzido, junto à ausência de expressão de proteínas responsáveis pelo acoplamento elétrico com o tecido miocárdico ( $\mathrm{N}$ caderina e conexina 43), podem ter sido relacionados a um aumento da incidência de arritmia ventricular após o tratamento ${ }^{27}$. Devido ao elevado risco de morte súbita em pacientes com taquicardia ventricular sustentada e disfunção ventricular, mesmo com a redução de eventos observada após início de amiodarona profilática antes das injeções de células, parece razoável admitir que tal terapia deva ser restrita a estudos envolvendo pacientes já portadores ou com indicação de implante de cardioversor-desfibrilador.

\section{Células Mononucleares Derivadas da Medula Óssea}

Trabalhos clínicos iniciais, em pacientes sem condições de realização de procedimentos de revascularização, demonstraram o benefício da injeção de CMMO na melhora dos sintomas, bem como o perfil de segurança da injeção intramiocárdica via mapeamento eletromecânico com cateter de NOGA (Tabela 1) 15,16,28,29. Novamente, a anatomia coronária complexa e a gravidade do estado avançado de doença dos pacientes incluídos nestes estudos impediram o uso das vias intracoronária ou transepicárdica. A heterogeneidade do tecido miocárdico nestes casos, com áreas de perfusão e contratilidade normais, muitas vezes entremeadas por tecido fibrótico, tecido isquêmico e miocárdio hibernado, dificulta sobremaneira a identificação de sítios de injeção. A vantagem do mapeamento eletroanatômico, o qual provê ao examinador informações sobre contratilidade e voltagem segmentares de maneira precisa, permite a identificação das bordas do miocárdio infartado (Figura 1), onde se encontra o maior número de cardiomiócitos isquêmicos, com potencial de recuperação após melhora de perfusão local. Estudo clínico randomizado revelou a segurança da injeção de CMMO com uso do cateter Myostar (Biosense Webester), em região peri-infarto de pacientes considerados "sem opções" para revascularização miocárdica. Neste trabaIho, Tse et al. ${ }^{30}$ obtiveram melhora de fração de ejeção e redução de defeito de perfusão à cintilografia, acompanhados de um aumento de capacidade funcional acessada por teste ergométrico.

De maneira distinta à dos mioblastos extraídos por biópsia muscular e expandidos em meios de cultura, as CMMO são obtidas por aspirado de medula óssea, a partir de gradiente de densidade em meio Ficoll, podendo ser administradas horas após sua seleção. Esta população celular é heterogênea, consistindo na verdade em várias subpopulações distintas, sendo neste caso mais difícil atribuir resultados a um tipo celular específico. Outra importante diferença seria a capacidade de induzir angiogênese, melhorando a perfusão local e, portanto, contribuindo para a redução de isquemia, recrutamento de tecido miocárdico hibernado, 
TABELA 1

Estudos clínicos com CMMO

\begin{tabular}{|c|c|c|c|c|c|c|c|}
\hline Estudo & $\mathbf{n}$ & Concentração & Via & Clínica & Objetivo & Tempo & Resultados \\
\hline Tse et al.[28] & $\begin{array}{c}8 \text { sem } \\
\text { controle }\end{array}$ & n.a. & $\begin{array}{l}\text { Intramio- } \\
\text { cárdica, } \\
\text { NOGA }\end{array}$ & $\begin{array}{l}\text { Angina } \\
\text { refratária }\end{array}$ & Segurança & 3 meses & $\begin{array}{c}\text { Melhora da } \\
\text { angina freq., reg. } \\
\text { contratilidade e } \\
\text { perfusão }\end{array}$ \\
\hline Perin et al.[15] & $\begin{array}{c}21 \text { não } \\
\text { randomizados }\end{array}$ & $\begin{array}{c}25,5 \pm 6,3 \\
\text { milhões }\end{array}$ & $\begin{array}{l}\text { Intramio- } \\
\text { cárdica, } \\
\text { NOGA }\end{array}$ & $\begin{array}{l}\text { Sem opção } \\
\text { de revascu- } \\
\text { larização }\end{array}$ & Segurança & 2 meses & $\begin{array}{l}\text { Melhora de } \\
\text { perfusão, } \\
\text { contratilidade } \\
\text { segmentar e } \\
\text { global }\end{array}$ \\
\hline Perin et al.[16] & $\begin{array}{c}20 \text { não } \\
\text { randomizados }\end{array}$ & $\begin{array}{c}25,5 \pm 6,3 \\
\text { milhões }\end{array}$ & $\begin{array}{l}\text { Intramio- } \\
\text { cárdica, } \\
\text { NOGA }\end{array}$ & $\begin{array}{c}\text { Sem opção } \\
\text { de revascu- } \\
\text { larização }\end{array}$ & $\begin{array}{l}\text { Evolução de } \\
\text { perfusão à } \\
\text { cintilografia e } \\
\text { capacidade } \\
\text { funcional à } \\
\text { ergometria }\end{array}$ & $\begin{array}{l}6 \text { e } 12 \\
\text { meses }\end{array}$ & $\begin{array}{l}\text { Melhora de } \\
\text { sintomas, } \\
\text { perfusão e } \\
\text { capacidade } \\
\text { funcional }\end{array}$ \\
\hline Kinnaird et al[29] & $\begin{array}{c}10 \text { sem } \\
\text { controle }\end{array}$ & $\begin{array}{c}78 \pm 66 \\
\text { milhões }\end{array}$ & $\begin{array}{l}\text { Intramio- } \\
\text { cárdica, } \\
\text { NOGA }\end{array}$ & $\begin{array}{l}\text { Sem opção } \\
\text { de revascu- } \\
\text { larização }\end{array}$ & $\begin{array}{l}\text { Segurança } \\
\text { e avaliação } \\
\text { clínica e } \\
\text { de perfusao }\end{array}$ & 3 meses & $\begin{array}{l}\text { Melhora de } \\
\text { sintomas e } \\
\text { perfusão }\end{array}$ \\
\hline
\end{tabular}

aumento de contratilidade regional, melhora da função diastólica e redução de remodelamento ventricular ${ }^{31}$. Apesar de ainda controverso, é possível que algumas subpopulacões específicas, como aquela identificada pela presença do marcador de superfície c-kit, e ausência de Lin, tenham potencial de transdiferenciação e formação de cardiomiócitos quando injetados em miocárdio infartado ${ }^{32}$.

Efeitos adicionais à simples revascularização, em pacientes com infarto miocárdico antigo, foram observados em estudos clínicos. A realização de revascularização percutânea associada à administração por via intracoronária de $\mathrm{CMMO}$ revelou uma redução de área infartada com melhora de contratilidade regional e global, associada a um aumento local de metabolismo demonstrado por maior captação de FDG, quando comparada ao grupo controle (submetido somente a revascularização ${ }^{33}$. De maneira semelhante, a administração de células progenitoras circulantes derivadas da medula óssea, identificadas funcionalmente pela capacidade de ligação à lecitina e captação de LDL acetilado, após recanalização percutânea de oclusões crônicas, revelou resultados semelhantes aos anteriores $^{34}$. Adicionalmente aos possíveis múltiplos mecanismos terapêuticos observados com o uso de CMMO em pacientes com disfunção ventricular isquêmica, tal população parece ter excelente perfil de segurança, não tendo sido relacionada a eventos embólicos após administração coronária ou a indução de arritmias ventriculares. Seu fácil isolamento e sua rápida disponibilidade, dispensando a necessidade de cultura, confe- rem grande potencial para uso clínico futuro, caso estudos randomizados confirmem o benefício da terapia celular com CMMO em pacientes com cardiopatia dilatada de etiologia isquêmica.

\section{Células Mesenquimais da Medula Óssea}

Tais células constituem uma pequena subpopulação da medula óssea (menos de 0,01\% de todas as células nucleares) ${ }^{35}$, caracterizada pela ausência de marcador CD34 e CD 13327. Apesar de ainda não existir nenhum trabalho clínico com o uso desta população celular, em pacientes com insuficiência cardíaca de etiologia isquêmica, no momento da confecção deste manuscrito, o interesse pelas células mesenquimais cresce rapidamente, devido ao seu potencial de transdiferenciação em células endoteliais, células musculares lisas e cardiomiócitos. Sua baixa imunogenicidade e ainda seu potencial imunossupressor ${ }^{36,37}$ abrem um campo para pesquisa de transplantes alogênicos, o qual permitiria a realização de um banco de células, evitando os problemas logísticos da cultura de células autólogas e possibilitando a terapia celular em cenários clínicos de isquemia aguda.

Estudo pré-clínico revelou a capacidade de diferenciação de células mesenquimais autólogas quando injetadas por via transepicárdica em modelo canino de isquemia crônica ${ }^{38}$. Neste trabalho, Silva et al. ${ }^{38}$ observaram melhora de fração de ejeção no grupo tratado, sendo possível identificar, após 60 dias, diferenciação das células implantadas em células musculares lisas e endoteliais, mas não em cardiomiócitos. Tais achados 


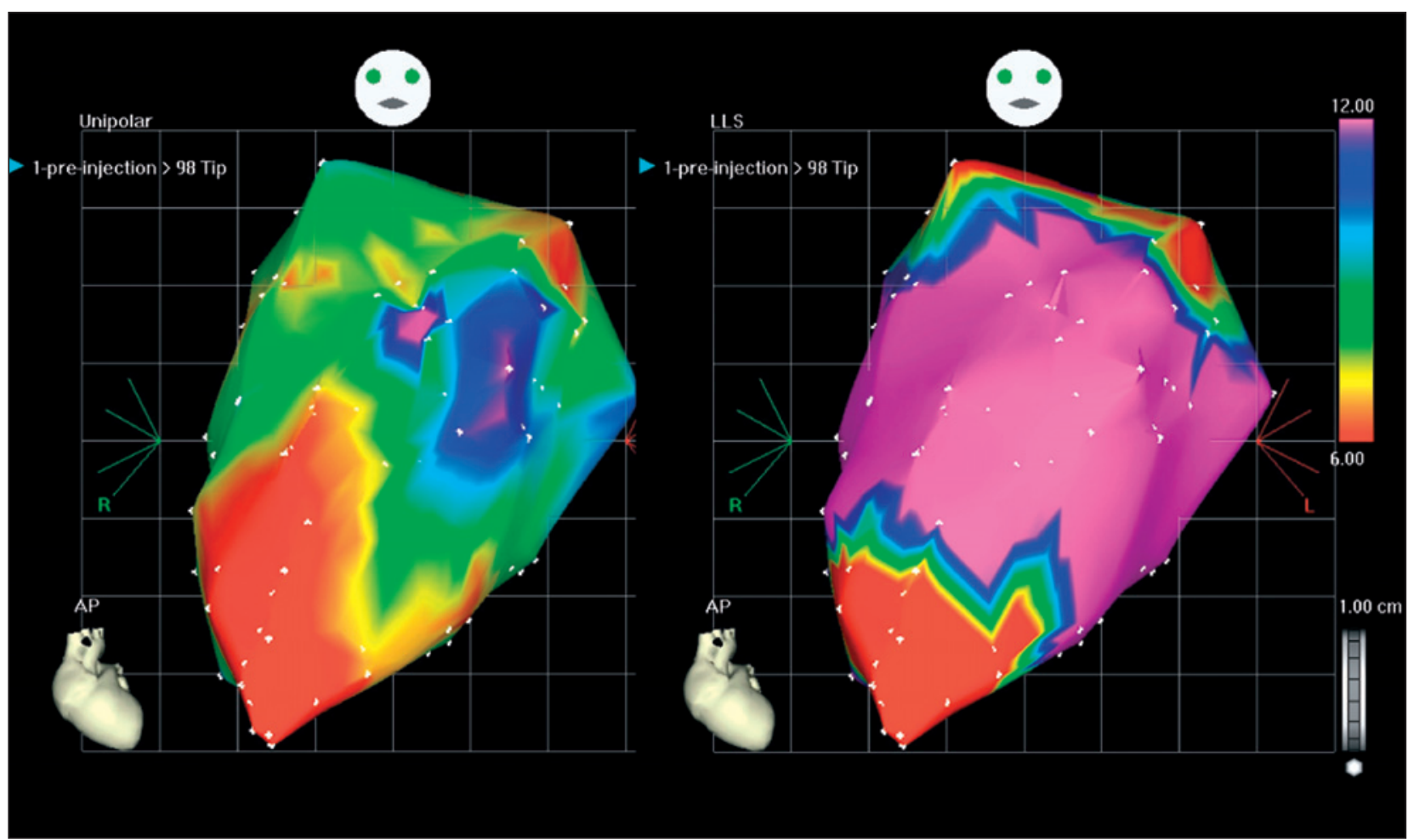

Figura 1 - Mapeamento eletroanatômico com uso de sistema NOGA (Biosense Webster), em modelo ovino de infarto agudo. À esquerda, exemplo de mapa de voltagem unipolar e, à direita, resultado de contratilidade ("linear local shortening"). Percebe-se a presença da área de infarto apical e sua transição com tecido miocárdico normal.

sugerem que a melhora, neste modelo de isquemia crônica, seria relacionada ao aumento da perfusão, secundária à angiogênese induzida pela terapia celular, sendo semelhantes a achados de estudos realizados em isquemia aguda em ratos $^{39}$.

O potencial de miogênese das células mesenquimais humanas foi verificado após injeção em corações de ratos imunodeficientes ${ }^{40}$. Importante consideração deve ser feita, ao fato de que a sobrevida após a infusão foi baixa e que a grande maioria das células foi identificada em tecidos distintos ao miocárdio. Portanto, alternativas para aumentar a sobrevida das células transplantadas e sua incorporação ao tecido miocárdico devem ser estudadas. Neste sentido, a transfecção prévia à injeção intramiocárdica, com retrovírus passível de gerar uma hiperexpressão de gene Akt, resultou em maior sobrevida após o transplante de tais células e notável recuperação do miocárdio lesado pelo insulto isquêmico, impedindo remodelamento e hipertrofia muscular, além de reduzir inflamação e deposição de colágeno ${ }^{41}$. Adicionalmente ao potencial de miogênese e vasculogênese, existe suspeita que as $\mathrm{CM}$ exerçam efeito parácrino precoce, relacionado à melhora de função ventricular, antes mesmo da identificação da formação de novos miócitos ${ }^{42}$.

Por fim, vale ressaltar as particularidades das vias de administração relacionadas a esta população especí- fica. Estudos realizados com infusão intracoronária revelaram aumento enzimático precoce, associado a achados micro e macroscópicos de infarto nos territórios correspondentes à artéria utilizada para as injeções ${ }^{43,44}$. A explicação para tais eventos seria uma obstrução microvascular após a injeção, devido ao seu maior tamanho celular ou à formação de agregados. Portanto, tal via deve ser evitada em estudos clínicos, antes que novos dados sejam disponibilizados. A redistribuição das CM após a infusão ainda é pouco definida e estudos utilizando marcadores identificáveis por ressonância nuclear magnética podem trazer resultados importantes para o melhor entendimento deste processo ${ }^{45}$. A comparação de injeção periférica e intracavitária, em ratos submetidos à oclusão coronária, revelou maior eficácia desta última via, principalmente por reduzir a sua captação ao nível da circulação pulmonar ${ }^{46}$.

Portanto, o universo futuro para a aplicação clínica das CM é bastante promissor.

O esclarecimento de questões, como segurança das vias de injeção e uso de células alogênicas ou geneticamente modificadas, será necessário para a evolução de tal terapia.

\section{Células Endoteliais Progenitoras}

A identificação de células endoteliais progenitoras (CEP) pode ser feita tanto a partir de marcadores de 
superfície (VEGFR-2, CD34, AC 133), como funcionalmente, pela capacidade de incorporação de LDL acetilado $^{47}$. Seu papel na manutenção da hemostasia vascular, tanto ao nível de microcirculação, quanto no endotélio de vasos maiores, tem sido recentemente foco de intenso estudo, contribuindo para o melhor entendimento das doenças isquêmicas cardíacas.

Como discutido anteriormente, a população de CEP circulantes provenientes da medula óssea sofre direta e imediatamente o impacto do insulto isquêmico, apresentando rápida resposta, caracterizada por aumento da sua concentração no miocárdio em sofrimento e conseqüente redução de sua contagem na circulação periférica ${ }^{48}$. Tal resposta foi identificada em estudos pré-clínicos, após pequenos períodos de isquemia transitória seguidos de reperfusão, estando portanto relacionada ao efeito protetor do pré-condicionamento isquêmico. Outras evidências de efeito protetor ou talvez melhor, efeito "reparador" desta população celular, provêem da correlação entre seu número e função, com a incidência de eventos cardiovasculares adversos. Estudos clínicos revelaram a correlação entre número e função das CEP, mostrando haver redução destas em pacientes com doença coronária estabelecida ${ }^{11,12,49,50}$. Adicionalmente, estabelecidos fatores risco para doença aterosclerótica, como idade e diabetes, estão associados à redução da função e contagem destas células ${ }^{5,6}$.

Apesar das evidências apresentadas em estudos clínicos e pré-clínicos do efeito benéfico reparador das CEP, tal população pode estar relacionada também com o processo de desenvolvimento da aterosclerose. A neoformação vascular e a proliferação desordenada da vasa-vasorum foram descritas como possíveis mecanismos de aumento de conteúdo de colesterol nas placas de ateroma, contribuindo para aumento da reação inflamatória, conseqüente afilamento da cápsula fibrosa, vulnerabilidade à ruptura e, portanto, à ocorrência de eventos isquêmicos adversos ${ }^{51}$. Estudos clínicos envolvendo pequeno número de pacientes demonstraram elevada incidência de reestenose após a infusão intracoronária de CEP em pacientes com IAM reperfundido, submetidos a implante de stent coronário ${ }^{52}$. Finalmente, foram identificadas pela presença de cromossomo $\mathrm{Y}$ em corações de pacientes do sexo masculino submetidos a transplante a partir de doadores do sexo feminino, que as CEP estão presentes em variada freqüência e intensidade, aparentemente relacionadas ao grau de insulto vascular, sendo sugerido seu papel no processo de rejeição e no desenvolvimento de aterosclerose coronária no coração transplantado ${ }^{53,54}$.

A utilização das CEP para o tratamento da cardiopatia isquêmica ainda persiste como incerta. Drogas de comprovada eficácia clínica e perfil de segurança, como ramipril e estatinas, podem ser utilizadas como estímulo ao recrutamento e aumento da população de CEP circulantes ${ }^{55,56}$. Outras drogas, como G-CSF, são também capazes de induzir mobilização, entretanto, o relato de eventos adversos, principalmente em pacientes com doença coronária crônica, depõe contra o seu uso neste sentido até que tenhamos novas evidênci$a^{57,58}$. A pequena quantidade de estudos clínicos com o uso de tal população celular no contexto de isquemia miocárdica impede qualquer aferição a respeito do seu possível papel terapêutico. A infusão intracoronária após recanalização de oclusão crônica mostrou resultados positivos, com melhora de microcirculação distal e redução de área de miocárdio hibernado, quando comparada à simples recanalização ${ }^{34}$. Estudo pré-clínico realizado por Kawamoto et al. ${ }^{59}$, com injeções intramiocárdicas com uso do sistema NOGA, revelou melhora de densidade capilar e fluxo colateral em modelo suíno de isquemia crônica, encorajando a realização de trabalhos clínicos no futuro.

\section{PERSPECTIVAS FUTURAS}

A terapia celular como todo novo tratamento em potencial, após a passagem por uma fase de euforia inicial, atualmente sofre uma relativa redução de crédito aos olhos da comunidade médica, muito desta relacionada aos "resultados negativos" de dois trabalhos clínicos recentemente publicados, mostrando ausência de melhora na fração de ejeção após administração intracoronária de CMMO em IAM reperfundido e perda de resultado positivo inicial após acompanhamento de 18 meses $^{60,61}$. Tais dados contribuem para o amadurecimento deste novo tratamento, no sentido de revelar suas limitações e encontrar suas possíveis indicações. Atualmente, ainda não sabemos qual tipo celular, via, dose e freqüência de administração comprovarão benefícios sólidos para o seu estabelecimento como opção terapêutica no tratamento da disfunção ventricular isquêmica. Entretanto, a evidência de uma resposta reparativa cardíaca e a possibilidade de desenvolvimento de estratégias terapêuticas que visam melhorar tais mecanismos, no sentido de torná-los clinicamente eficazes e talvez alcançar até mesmo um potencial regenerativo, nos levam a acreditar que um novo capítulo na evolução do tratamento das doenças cardiovasculares começa a ser escrito.

\section{REFERÊNCIAS BIBLIOGRÁFICAS}

1. Hunt SA, Abraham WT, Chin MH, Feldman AM, Francis GS, Ganiats TG, et al. ACC/AHA 2005 Guideline Update for the Diagnosis and Management of Chronic Heart Failure in the Adult: a report of the American College of Cardiology/American Heart Association Task Force on Practice Guidelines (Writing Committee to Update the 2001 Guidelines for the Evaluation and Management of Heart Failure): developed in collaboration with the American College of Chest Physicians and the International Society for Heart and Lung Transplantation: endorsed by the Heart Rhythm Society. Circulation. 2005;112(12):e154-235.

2. Mouquet F, Pfister O, Jain M, Oikonomopoulos A, Ngoy $S$, Summer R, et al. Restoration of cardiac progenitor cells after myocardial infarction by self-proliferation and selective homing of bone marrow-derived stem cells. Circ Res. 2005;97(11):1090-2. 
3. Beltrami AP, Barlucchi L, Torella D, Baker M, Limana F, Chimenti $S$, et al. Adult cardiac stem cells are multipotent and support myocardial regeneration. Cell. 2003;114(6):763-76.

4. Quaini F, Urbanek K, Beltrami AP, Finato N, Beltrami CA, Nadal-Ginard B, et al. Chimerism of the transplanted heart. N Engl J Med. 2002;346(1):5-15.

5. Heiss C, Keymel S, Niesler U, Ziemann J, Kelm M, Kalka C. Impaired progenitor cell activity in age-related endothelial dysfunction. J Am Coll Cardiol. 2005;45(9):1441-8.

6. Fadini GP, Miorin M, Facco M, Bonamico S, Baesso I, Grego $F$, et al. Circulating endothelial progenitor cells are reduced in peripheral vascular complications of type 2 diabetes mellitus. J Am Coll Cardiol. 2005;45(9):1449-57.

7. Méndez-Ferrer S, Ellison GM, Torella D, Nadal-Ginard B. Resident progenitors and bone marrow stem cells in myocardial renewal and repair. Nat Clin Pract Cardiovasc Med. 2006;3(Suppl 1):S83-9.

8. Hunter JJ, Chien KR. Signaling pathways for cardiac hypertrophy and failure. N Engl J Med. 1999;341(17):1276-83.

9. Hassink RJ, Brutel de la Rivière A, Mummery $C L$, Doevendans PA. Transplantation of cells for cardiac repair. J Am Coll Cardiol. 2003;41(5):711-7.

10. Gill M, Dias S, Hattori K, Rivera ML, Hicklin D, Witte L, et al. Vascular trauma induces rapid but transient mobilization of VEGFR2(+)AC133(+) endothelial precursor cells. Circ Res. 2001;88(2):167-74.

11. Vasa M, Fichtlscherer S, Aicher A, Adler K, Urbich C, Martin $\mathrm{H}$, et al. Number and migratory activity of circulating endothelial progenitor cells inversely correlate with risk factors for coronary artery disease. Circ Res. 2001;89(1):E1-7.

12. Schmidt-Lucke $C$, Rössig L, Fichtlscherer S, Vasa M, Britten $M$, Kämper $U$, et al. Reduced number of circulating endothelial progenitor cells predicts future cardiovascular events: proof of concept for the clinical importance of endogenous vascular repair. Circulation. 2005;111(22):2981-7.

13. Chareonthaitawee P, Gersh BJ, Araoz PA, Gibbons RJ. Revascularization in severe left ventricular dysfunction: the role of viability testing. J Am Coll Cardiol. 2005;46(4):567-74.

14. Udelson JE, Coleman PS, Metherall J, Pandian NG, Gomez AR, Griffith JL, et al. Predicting recovery of severe regional ventricular dysfunction. Comparison of resting scintigraphy with 201TI and 99mTc-sestamibi. Circulation. 1994;89(6):2552-61.

15. Perin EC, Dohmann HF, Borojevic R, Silva SA, Sousa AL, Mesquita CT, et al. Transendocardial, autologous bone marrow cell transplantation for severe, chronic ischemic heart failure. Circulation. 2003;107(18):2294-302.

16. Perin EC, Dohmann HF, Borojevic R, Silva SA, Sousa AL, Silva GV, et al. Improved exercise capacity and ischemia 6 and 12 months after transendocardial injection of autologous bone marrow mononuclear cells for ischemic cardiomyopathy. Circulation. 2004;110(11 Suppl 1):II213-8.

17. Menasche $P$, Hagege AA, Vilquin JT, Desnos $M$, Abergel E, Pouzet B, et al. Autologous skeletal myoblast transplantation for severe postinfarction left ventricular dysfunction. J Am Coll Cardiol. 2003;41(7):1078-83.

18. Siminiak T, Kalawski R, Fiszer D, Jerzykowska O, RzeŸniczak J, Rozwadowska N, et al. Autologous skeletal myoblast transplantation for the treatment of postinfarction myocardial injury: phase I clinical study with 12 months of follow-up. Am Heart J. 2004;148(3):531-7.

19. Pagani FD, DerSimonian H, Zawadzka A, Wetzel K, Edge AS, Jacoby DB, et al. Autologous skeletal myoblasts transplanted to ischemia-damaged myocardium in humans. Histological analysis of cell survival and differentiation. J Am Coll Cardiol. 2003;41(5):879-88.
20. Steendijk P, Smits PC, Valgimigli M, van der Giessen WJ, Onderwater EE, Serruys PW. Intramyocardial injection of skeletal myoblasts: long-term follow-up with pressure-volume loops. Nat Clin Pract Cardiovasc Med. 2006;3(Suppl 1):S94-100.

21. Dib N, Michler RE, Pagani FD, Wright S, Kereiakes DJ, Lengerich R, et al. Safety and feasibility of autologous myoblast transplantation in patients with ischemic cardiomyopathy: four-year follow-up. Circulation. 2005;112(12):1748-55.

22. Siminiak T, Fiszer D, Jerzykowska O, Grygielska B, Rozwadowska $\mathrm{N}, \mathrm{Ka}^{3}$ mucki $\mathrm{P}$, et al. Percutaneous trans-coronaryvenous transplantation of autologous skeletal myoblasts in the treatment of post-infarction myocardial contractility impairment: the POZNAN trial. Eur Heart J. 2005;26(12):1188-95.

23. Siminiak T, Burchardt $P$, Kurpisz M. Postinfarction heart failure: surgical and trans-coronary-venous transplantation of autologous myoblasts. Nat Clin Pract Cardiovasc Med. 2006;3(Suppl 1):S46-51.

24. Kornowski R, Hong MK, Gepstein L, Goldstein S, Ellahham S, Ben-Haim SA, et al. Preliminary animal and clinical experiences using an electromechanical endocardial mapping procedure to distinguish infarcted from healthy myocardium. Circulation. 1998;98(11):1116-24.

25. Perin EC, Silva GV, Sarmento-Leite R, Sousa AL, Howell M, Muthupillai R, et al. Assessing myocardial viability and infarct transmurality with left ventricular electromechanical mapping in patients with stable coronary artery disease: validation by delayed-enhancement magnetic resonance imaging. Circulation. 2002;106(8):957-61.

26. Opie SR, Dib N. Surgical and catheter delivery of autologous myoblasts in patients with congestive heart failure. Nat Clin Pract Cardiovasc Med. 2006;3(Suppl 1):S42-5.

27. Wollert KC, Drexler H. Clinical applications of stem cells for the heart. Circ Res. 2005;96(2):151-63.

28. Tse HF, Kwong YL, Chan JK, Lo G, Ho CL, Lau CP. Angiogenesis in ischaemic myocardium by intramyocardial autologous bone marrow mononuclear cell implantation. Lancet. 2003;361(9351):47-9.

29. Kinnaird T, Stabile E, Burnett MS, Lee CW, Barr S, Fuchs $S$, et al. Marrow-derived stromal cells express genes encoding a broad spectrum of arteriogenic cytokines and promote in vitro and in vivo arteriogenesis through paracrine mechanisms. Circ Res. 2004;94(5):678-85.

30. Tse HF. PROTECT-CAD. 2006. Available from: http:// www.theheart.org/article/670615.do

31. Kocher AA, Schuster MD, Szabolcs MJ, Takuma S, Burkhoff D, Wang J, et al. Neovascularization of ischemic myocardium by human bone-marrow-derived angioblasts prevents cardiomyocyte apoptosis, reduces remodeling and improves cardiac function. Nat Med. 2001;7(4):430-6.

32. Orlic D, Kajstura J, Chimenti S, Jakoniuk I, Anderson SM, $\mathrm{Li} B$, et al. Bone marrow cells regenerate infarcted myocardium. Nature. 2001;410(6829):701-5.

33. Strauer BE, Brehm M, Zeus T, Bartsch T, Schannwell C, Antke $C$, et al. Regeneration of human infarcted heart muscle by intracoronary autologous bone marrow cell transplantation in chronic coronary artery disease: the IACT Study. J Am Coll Cardiol. 2005;46(9):1651-8.

34. Erbs S, Linke A, Adams V, Lenk K, Thiele H, Diederich KW, et al. Transplantation of blood-derived progenitor cells after recanalization of chronic coronary artery occlusion: first randomized and placebo-controlled study. Circ Res. 2005;97(8):756-62.

35. Wollert KC, Drexler H. Mesenchymal stem cells for myocardial infarction: promises and pitfalls. Circulation. 2005;112(2): $151-3$. 
36. Tse WT, Pendleton JD, Beyer WM, Egalka MC, Guinan EC. Suppression of allogeneic T-cell proliferation by human marrow stromal cells: implications in transplantation. Transplantation. 2003;75(3):389-97.

37. Le Blanc K, Rasmusson I, Sundberg B, Götherström C, Hassan M, Uzunel M, et al. Treatment of severe acute graftversus-host disease with third party haploidentical mesenchymal stem cells. Lancet. 2004;363(9419):1439-41.

38. Silva GV, Litovsky S, Assad JA, Sousa AL, Martin BJ, Vela $D$, et al. Mesenchymal stem cells differentiate into an endothelial phenotype, enhance vascular density, and improve heart function in a canine chronic ischemia model. Circulation. 2005;111(2):150-6.

39. Davani S, Marandin A, Mersin N, Royer B, Kantelip B, Hervé $P$, et al. Mesenchymal progenitor cells differentiate into an endothelial phenotype, enhance vascular density, and improve heart function in a rat cellular cardiomyoplasty model. Circulation. 2003;108(Suppl 1):II253-8.

40. Toma C, Pittenger MF, Cahill KS, Byrne BJ, Kessler PD. Human mesenchymal stem cells differentiate to a cardiomyocyte phenotype in the adult murine heart. Circulation. 2002;105(1): 93-8.

41. Mangi AA, Noiseux N, Kong D, He H, Rezvani M, Ingwall JS, et al. Mesenchymal stem cells modified with Akt prevent remodeling and restore performance of infarcted hearts. Nat Med. 2003;9(9):1195-201.

42. Dai W, Hale SL, Martin BJ, Kuang JQ, Dow JS, Wold LE, et al. Allogeneic mesenchymal stem cell transplantation in postinfarcted rat myocardium: short- and long-term effects. Circulation. 2005;112(2):214-23.

43. Vulliet PR, Greeley M, Halloran SM, MacDonald KA, Kittleson MD. Intra-coronary arterial injection of mesenchymal stromal cells and microinfarction in dogs. Lancet. 2004;363(9411): 783-4.

44. Matsubara H. Risk to the coronary arteries of intracoronary stem cell infusion and G-CSF cytokine therapy. Lancet. 2004;363(9411):746-7.

45. Hill JM, Dick AJ, Raman VK, Thompson RB, Yu ZX, Hinds $K A$, et al. Serial cardiac magnetic resonance imaging of injected mesenchymal stem cells. Circulation. 2003;108(8): 1009-14.

46. Barbash IM, Chouraqui P, Baron J, Feinberg MS, Etzion S, Tessone A, et al. Systemic delivery of bone marrow-derived mesenchymal stem cells to the infarcted myocardium: feasibility, cell migration, and body distribution. Circulation. 2003;108(7):863-8.

47. Peichev M, Naiyer AJ, Pereira D, Zhu Z, Lane WJ, Williams $M$, et al. Expression of VEGFR-2 and AC133 by circulating human $\mathrm{CD} 34(+)$ cells identifies a population of functional endothelial precursors. Blood. 2000;95(3):952-8.

48. Ii M, Nishimura $H$, Iwakura A, Wecker A, Eaton E, Asahara $\mathrm{T}$, et al. Endothelial progenitor cells are rapidly recruited to myocardium and mediate protective effect of ischemic preconditioning via "imported" nitric oxide synthase activity. Circulation. 2005;111(9):1114-20.

49. Heeschen C, Lehmann R, Honold J, Assmus B, Aicher A,
Walter $\mathrm{DH}$, et al. Profoundly reduced neovascularization capacity of bone marrow mononuclear cells derived from patients with chronic ischemic heart disease. Circulation. 2004;109(13):1615-22.

50. Werner N, Kosiol S, Schiegl T, Ahlers P, Walenta K, Link A, et al. Circulating endothelial progenitor cells and cardiovascular outcomes. N Engl J Med. 2005;353(10):999-1007.

51. Virmani R, Kolodgie FD, Burke AP, Finn AV, Gold HK, Tulenko TN, et al. Atherosclerotic plaque progression and vulnerability to rupture: angiogenesis as a source of intraplaque hemorrhage. Arterioscler Thromb Vasc Biol. 2005;25(10): 2054-61.

52. Bartunek J, Vanderheyden M, Vandekerckhove B, Mansour $\mathrm{S}$, De Bruyne B, De Bondt $\mathrm{P}$, et al. Intracoronary injection of CD133-positive enriched bone marrow progenitor cells promotes cardiac recovery after recent myocardial infarction: feasibility and safety. Circulation. 2005;112(9 Suppl):I178-83.

53. Minami E, Laflamme MA, Saffitz JE, Murry CE. Extracardiac progenitor cells repopulate most major cell types in the transplanted human heart. Circulation. 2005;112(19):2951-8.

54. Hillebrands JL, Onuta G, Rozing J. Role of progenitor cells in transplant arteriosclerosis. Trends Cardiovasc Med. 2005;15 (1): $1-8$.

55. Min TQ, Zhu CJ, Xiang WX, Hui ZJ, Peng SY. Improvement in endothelial progenitor cells from peripheral blood by ramipril therapy in patients with stable coronary artery disease. Cardiovasc Drugs Ther. 2004;18(3):203-9.

56. Vasa M, Fichtlscherer S, Adler K, Aicher A, Martin H, Zeiher $\mathrm{AM}$, et al. Increase in circulating endothelial progenitor cells by statin therapy in patients with stable coronary artery disease. Circulation. 2001;103(24):2885-90.

57. Hill JM, Syed MA, Arai AE, Powell TM, Paul JD, Zalos G, et al. Outcomes and risks of granulocyte colony-stimulating factor in patients with coronary artery disease. J Am Coll Cardiol. 2005;46(9):1643-8.

58. Sinha S, Poh KK, Sodano D, Flanagan J, Ouilette C, Kearney $M$, et al. Safety and efficacy of peripheral blood progenitor cell mobilization and collection in patients with advanced coronary heart disease. J Clin Apher. 2006;21(2):116-20.

59. Kawamoto A, Tkebuchava T, Yamaguchi J, Nishimura H, Yoon YS, Milliken C, et al. Intramyocardial transplantation of autologous endothelial progenitor cells for therapeutic neovascularization of myocardial ischemia. Circulation. 2003;107(3):461-8.

60. Janssens S, Dubois C, Bogaert J, Theunissen K, Deroose C, Desmet $W$, et al. Autologous bone marrow-derived stemcell transfer in patients with ST-segment elevation myocardial infarction: double-blind, randomised controlled trial. Lancet. 2006;367(9505):113-21.

61. Meyer GP, Wollert KC, Lotz J, Steffens J, Lippolt P, Fichtner $\mathrm{S}$, et al. Intracoronary bone marrow cell transfer after myocardial infarction: eighteen months' follow-up data from the randomized, controlled BOOST (BOne marrOw transfer to enhance ST-elevation infarct regeneration) trial. Circulation. 2006;113(10):1287-94. 